\title{
Elevated plasma heparin-binding protein is associated with early death after resuscitation from cardiac arrest
}

\author{
Giuseppe Ristagno ${ }^{1}$, Serge Masson ${ }^{1}$, Marjaana Tiainen², Stepani Bendel ${ }^{3}$, Roberto Bernasconi ${ }^{1}$, Tero Varpula $^{4}$, \\ Valentina Milani ${ }^{1}$, Jukka Vaahersalo ${ }^{4}$, Michela Magnoli', Eberhard Spanuth ${ }^{5}$, Simona Barlera', Roberto Latini ${ }^{1}$, \\ Sanna Hoppu ${ }^{6}$, Ville Pettilä ${ }^{4,7}$, Markus B. Skrifvars ${ }^{4,8^{*}}$ and FINNRESUSCI Study Group
}

\begin{abstract}
Background: An intense systemic inflammatory response is observed following reperfusion after cardiac arrest. Heparin-binding protein (HBP) is a granule protein released by neutrophils that intervenes in endothelial permeability regulation. In the present study, we investigated plasma levels of HBP in a large population of patients resuscitated from out-of-hospital cardiac arrest. We hypothesized that high circulating levels of HBP are associated with severity of post-cardiac arrest syndrome and poor outcome.

Methods: Plasma was obtained from 278 patients enrolled in a prospective multicenter observational study in 21 intensive care units (ICU) in Finland. HBP was assayed at ICU admission and $48 \mathrm{~h}$ later. Multiple organ dysfunction syndrome (MODS) was defined as the $24 \mathrm{~h}$ Sequential Organ Failure Assessment (SOFA) score $\geq 12$. ICU death and 12-month Cerebral Performance Category (CPC) were evaluated. Multiple linear and logistic regression tests and receiver operating characteristic curves with area under the curve (AUC) were performed.

Results: Eighty-two percent of patients (229 of 278) survived to ICU discharge and $48 \%$ (133 of 276) to 1 year with a favorable neurological outcome (CPC 1 or 2). At ICU admission, median plasma levels of HBP were markedly elevated, 15.4 [9.6-31.3] ng/mL, and persisted high $48 \mathrm{~h}$ later, 14.8 [9.8-31.1] ng/mL. Admission levels of HBP were higher in patients who had higher $24 \mathrm{~h}$ SOFA and cardiovascular SOFA score $(p<0.0001)$ and in those who developed MODS compared to those who did not (29.3 [13.7-60.1] ng/mL vs. 13.6 [9.1-26.2] ng/mL, $p<0.0001$; AUC $=0.70 \pm 0.04, p=0.0001$ ). Admission levels of HBP were also higher in patients who died in ICU (31.0 [17.7-78.2] ng/mL) compared to those who survived $(13.5[9.1-25.5] \mathrm{ng} / \mathrm{mL}, p<0.0001)$ and in those with an unfavorable 12-month neurological outcome compared to those with a favorable one (18.9 [11.3-44.3] ng/mL vs. 12.8 [8.6-30.4] ng/mL, $p<0.0001$ ). Admission levels of HBP predicted early ICU death with an AUC of $0.74 \pm 0$. $04(p<0.0001)$ and were independently associated with ICU death (OR [95 \%CI] $1.607[1.076-2.399], p=0.020)$, but not with unfavorable 12-month neurological outcome (OR [95 \%Cl] 1.154 [0.834-1.596], $p=0.387$ ).
\end{abstract}

Conclusions: Elevated plasma levels of HBP at ICU admission were independently associated with early death in ICU.

Keywords: Cardiac arrest, Heparin-binding protein, Post resuscitation, Outcome

\footnotetext{
*Correspondence: markus.skrifvars@hus.fi

${ }^{4}$ Division of Intensive Care Medicine, Department of Anaesthesiology, Intensive Care and Pain Medicine, University of Helsinki and Helsinki University Hospital, Topeliuksenkatu 5, PL 266, 00029 HUS, Helsinki, Finland

${ }^{8}$ Australian and New Zealand Intensive Care Research Centre, School of Public Health and Preventive Medicine, Monash University, Melbourne, Victoria, Australia

Full list of author information is available at the end of the article
}<smiles></smiles>

(c) 2016 The Author(s). Open Access This article is distributed under the terms of the Creative Commons Attribution 4.0 International License (http://creativecommons.org/licenses/by/4.0/), which permits unrestricted use, distribution, and reproduction in any medium, provided you give appropriate credit to the original author(s) and the source, provide a link to the Creative Commons license, and indicate if changes were made. The Creative Commons Public Domain Dedication waiver (http://creativecommons.org/publicdomain/zero/1.0/) applies to the data made available in this article, unless otherwise stated. 


\section{Background}

Despite initially successful resuscitation, mortality after cardiac arrest remains high, with more than half of patients not surviving to hospital discharge due to "postcardiac arrest syndrome" [1, 2]. Beside myocardial dysfunction and evolving brain injury, a prominent pathophysiological process characterizing such a syndrome is the systemic inflammation subsequent to whole-body ischemia/reperfusion [2-6]. Accordingly, the systemic inflammatory response observed after cardiopulmonary resuscitation (CPR) provides evident similarities to sepsis and septic shock, with progression toward circulatory failure and multiple organ dysfunction syndrome (MODS) $[4,5]$. Indeed, severe organ dysfunction in two or more organ systems is very common in post-cardiac arrest patients and is associated with early mortality [7].

Heparin-binding protein (HBP), also called azurocidin or cationic antimicrobial protein of $37 \mathrm{kDa}$, is a multifunctional protein contained within the secretory and azurophilic granules of polymorphonuclear leukocytes, and is rapidly released upon adhesion of leukocytes to endothelial cells. Once released, HBP acts as chemoattractant and activator of monocytes and macrophages, and increases vascular permeability with consequent edema and hypoperfusion $[8,9]$.

The systemic inflammatory response following resuscitation from cardiac arrest includes leukocyte activation, endothelial injury, and vascular response with vascular leakage; thus, elevation in plasma levels of HBP is expected and might represent a potential prognostic marker [2-4]. Indeed, in a small cohort of cardiac arrest patients, early elevation of HBP after resuscitation predicted organ failure and poor long-term neurological outcome [10]. In the present observational study, we examined HBP plasma levels in a large population of patients resuscitated from out-of-hospital cardiac arrest. Since HBP has been shown to predict circulatory failure and increase risk of death in the critically ill patient [9-12], we hypothesized that high circulating levels of $\mathrm{HBP}$ in patients resuscitated from cardiac arrest would be associated with the severity of organ dysfunction and early death.

\section{Methods}

\section{Study design, setting, and selection of participants}

The study was an observational cohort study, in which plasma levels of HBP were assessed in adult patients resuscitated from out-of-hospital cardiac arrest. Patients included in the present study were part of the FINNRESUSCI study, a nationwide prospective observational cohort study conducted in 21 hospitals in Finland between March 1, 2010 and February 28, 2011 and aiming to evaluate post-resuscitation care and outcome of out-of-hospital cardiac arrest [13]. The study was approved by the ethics committee of the Helsinki and
Uusimaa Hospital district (FINNRESUSCI TUTKIMUS $\$ 10,20.1 .201)$ in addition to local ethics approvals in six of the World Medical Association Declaration of Helsinki. Informed consent from the patient's next of kin was obtained for data collection and blood sampling. All cardiac arrest patients in whom blood samples were obtained at intensive care unit (ICU) admission were included in the study. Information on the 12-month neurological outcome was available for 276 patients. Thus, these 276 patients were included in the long-term outcome analysis.

\section{Data collection, processing, and outcomes}

The participating hospitals were a part of the Finnish Intensive Care Consortium (FICC) and used the same electronic data management system and data validation software (Web Validator, Tieto, Helsinki, Finland). Data on study patients were prospectively collected using an internet-based case report form. Pre-hospital data were collected by the paramedics in accordance with the Utstein Guidelines and included: whether the arrest was witnessed or not; the administration of bystander-initiated life support; the time from call to the dispatch center and return of spontaneous circulation (ROSC); and the use of adrenaline. In-hospital care data were collected electronically and comprised the use of vasopressors and induced hypothermia, the Sequential Organ Failure Assessment (SOFA) score, the Acute Physiology and Chronic Health Evaluation (APACHE) II score, and ICU mortality. The condition of MODS was defined as a SOFA score $\geq 12$ $[14,15]$. More specifically, the SOFA score was reported as worst value during the first 24 hours (h) of ICU care. A specialist in neurology blinded to the management in the ICU contacted patients discharged from the hospital by phone 1 year after cardiac arrest and determined neurological outcome according to the Pittsburgh Cerebral Performance Categories (CPC). We defined 12-month good outcome as CPC 1-2, and 12-month poor outcome as CPC 3-5.

\section{Methods of measurement}

Plasma levels of HBP at ICU admission and 48 hours later were measured blinded to case identity and clinical data. Blood samples were collected into ethylenediaminetetraacetic (EDTA) acid tubes and were kept at room temperature for 30-60 min before being centrifuged at $2200 \mathrm{~g}$ for $10 \mathrm{~min}$. Plasma samples were then frozen at $-20{ }^{\circ} \mathrm{C}$ in each participating hospital, prior to being transferred in frozen form to Kuopio University Hospital, where they were stored at $-70{ }^{\circ} \mathrm{C}$. Upon analysis, samples were thawed and divided into aliquots. HBP levels were assayed in a single batch using an enzyme immunoassay from Axis-Shield Diagnostics (Dundee, Scotland), according to manufacturer's recommendations. 
Limit of detection is reported to be $5.9 \mathrm{ng} / \mathrm{mL}$. Interassay coefficients of variation were measured in 11 replicates and were $11 \%$ at $21 \mathrm{ng} / \mathrm{mL}$ and $7 \%$ at $81 \mathrm{ng} / \mathrm{mL}$.

\section{Statistical analysis}

Categorical variables are presented as proportions and continuous variables as median with interquartile range (IQR). Baseline characteristics by outcomes occurrence were investigated with the chi-square test for categorical variables; continuous variables were compared by analysis of variance or by the nonparametric Kruskal-Wallis test for continuous non-normally distributed data. Multivariable linear regression was performed on natural logarithm-transformed HBP values to identify the independent factors at resuscitation influencing inflammatory biomarkers levels at ICU admission and $48 \mathrm{~h}$ later. Results of linear regression are reported in terms of percent change (exponential of beta coefficient) and $p$ values. Multivariable logistic regression was used to identify factors that were predictors of MODS, ICU mortality, and 12-month poor neurological outcome. Age, sex, and all other variables associated with the outcome in the univariate analysis $(p<0.05)$ were included in the multivariable model. Odds ratios (OR) with the corresponding $95 \%$ confidence interval (CI) were calculated and $p$ values were considered statistically significant if they were less than 0.05 . For each multivariable logistic model, collinearity and calibration were assessed respectively by value of variance inflaction factor (VIF) and Hosmer-Lemeshow test. The discrimination ability of inflammatory biomarkers was evaluated by receiver operating characteristic curve (ROC) analyses. All statistical analyses were performed with SAS software, version 9.2 (SAS Institute, Inc., Cary, NC, USA).

\section{Results}

The FINNIRESUSCI study included 548 patients [13], whose clinical characteristics are reported in Additional file 1. Among these, informed consent for blood sampling was obtained for 245 patients at the time of ICU admission and for an additional 33 patients prior to subsequent sampling $48 \mathrm{~h}$ later, giving a total study sample of 278 patients. For these 278 patients, data were available from 245 patients at ICU admission and from 222 patients $48 \mathrm{~h}$ later, due to either death or patient transfer. Eighty-two percent of patients (229 of 278) survived to ICU discharge and $48 \%$ (133 of 276) had favorable neurological outcome (CPC 1 or 2 ) at 12 months (Table 1). Baseline characteristics and factors influencing ICU survival and 12-month outcome are shown in Table 1. Pre-hospital factors univariately associated with ICU survival were a shockable rhythm, no use of adrenaline, a shorter time to ROSC, and the induction of hypothermia, while those associated with long-term survival and good neurological outcome included also a younger age and a witnessed cardiac arrest (Table 1).

Normal values for plasma HBP in the general population are approximately $6 \mathrm{ng} / \mathrm{mL}[16,17]$. In our patients, median plasma levels of HBP were more than twofold, 15.4 [9.6-31.3] $\mathrm{ng} / \mathrm{mL}$, at ICU admission and persisted high $48 \mathrm{~h}$ later $14.8[9.8-31.1] \mathrm{ng} / \mathrm{mL}$. Levels of HBP were significantly higher in patients with an initial nonshockable rhythm compared to those with a shockable rhythm, and in the instance of longer time to return of spontaneous circulation (ROSC) (Table 2). By linear regression models, the common independent determinants of levels of HBP were: the presence of a non-shockable rhythm (64\% increase from shockable to non-shockable, $p<0.0001$ at ICU admission, and $54 \%$ increase at $48 \mathrm{~h}$, $p=0.013)$ and a longer time to ROSC (1.6\% increase for each minute, $p=0.009$ at ICU admission).

Table 1 Baseline characteristics and clinical factors at resuscitation in all patients and between ICU survivors and non-survivors and patients with good and poor outcome at 12 months

\begin{tabular}{|c|c|c|c|c|c|}
\hline & \multirow{2}{*}{$\begin{array}{l}\text { Whole population } \\
(n=278)\end{array}$} & \multicolumn{2}{|l|}{ ICU survival } & \multicolumn{2}{|c|}{ 12-month neurological outcome ${ }^{\circ}$} \\
\hline & & Yes $(n=229)$ & No $(n=49)$ & Good $(n=133)$ & Poor $(n=143)$ \\
\hline Age, mean (SD) & $63 \pm 13$ & $63 \pm 12$ & $64 \pm 14$ & $60 \pm 12^{\S}$ & $65 \pm 13$ \\
\hline Sex (male), n (\%) & $229(82)$ & $189(83)$ & $40(82)$ & $109(82)$ & $119(83)$ \\
\hline Shockable rhythm, n (\%) & $180(65)$ & $163(71)^{* *}$ & $17(35)$ & $108(81)^{\S}$ & $71(50)$ \\
\hline Witnessed cardiac arrest, n (\%) & $254(91)$ & $212(93)$ & $42(86)$ & $128(96)^{\S}$ & $124(87)$ \\
\hline Bystander-initiated BLS, n (\%) & $158(57)$ & $133(58)$ & $25(51)$ & $82(62)$ & $76(53)$ \\
\hline Adrenaline used, n (\%) & $186(67)$ & $141(62)^{* *}$ & $45(92)$ & $67(50)^{\S}$ & $118(83)$ \\
\hline Time to ROSC in min, mean (SD) & $21 \pm 11$ & $20 \pm 11^{* *}$ & $25 \pm 10$ & $18 \pm 10^{\S}$ & $24 \pm 11$ \\
\hline Therapeutic hypothermia, n (\%) & $202(73)$ & $173(76)^{*}$ & $29(59)$ & $104(78)$ & $97(68)$ \\
\hline
\end{tabular}

Chi-square test for categorical variables; analysis of variance (ANOVA) for continuous variables

ICU intensive care unit, SD standard deviation, BLS basic life support, ROSC return of spontaneous circulation

${ }^{\circ}$ Data on 12-month survival/outcome were missing for two patients

${ }^{*} p<0.05$ and ${ }^{* *} p<0.01$ vs. ICU death; ${ }^{\S} p<0.01$ vs. poor outcome at 12 months 
Table 2 Heparin-binding protein (HBP) levels by age, cardiac arrest (CA) presenting rhythm, time to ROSC, and induced hypothermia

\begin{tabular}{|c|c|c|}
\hline Variable & $\mathrm{n}$ & $\begin{array}{l}\mathrm{HBP} \\
\mathrm{ng} / \mathrm{mL}\end{array}$ \\
\hline \multicolumn{3}{|l|}{ Admission levels } \\
\hline \multicolumn{3}{|l|}{ Age, year } \\
\hline$<59$ & 79 & $15.5(9.1-33.7)$ \\
\hline $59-68$ & 86 & $15.7(9.9-30.2)$ \\
\hline$>68$ & 80 & $14.5(9.9-31.5)$ \\
\hline$p$ value & & 0.967 \\
\hline \multicolumn{3}{|c|}{ CA presenting rhythm } \\
\hline Shockable & 154 & $13.1(8.9-21.5)$ \\
\hline Non-shockable & 90 & $21.5(11.4-46.1)$ \\
\hline$p$ value & & $<0.0001$ \\
\hline \multicolumn{3}{|l|}{ Time to ROSC, min } \\
\hline $1-15$ & 83 & $11.9(7.9-21.2)$ \\
\hline $16-24$ & 83 & $17.4(9.9-33.2)$ \\
\hline $25-57$ & 79 & $18.4(10.8-41.7)$ \\
\hline$p$ value & & 0.004 \\
\hline \multicolumn{3}{|l|}{48 hour levels } \\
\hline \multicolumn{3}{|l|}{ Age, year } \\
\hline$<59$ & 75 & $14.5(9.7-28.3)$ \\
\hline $59-68$ & 81 & $13.5(9.6-31.1)$ \\
\hline$>68$ & 66 & $15.7(11.7-31.7)$ \\
\hline$p$ value & & 0.619 \\
\hline \multicolumn{3}{|c|}{ CA presenting rhythm } \\
\hline Shockable & 159 & $14.1(9.7-26.1)$ \\
\hline Non-shockable & 63 & $19.6(10.0-59.0)$ \\
\hline$p$ value & & 0.023 \\
\hline \multicolumn{3}{|l|}{ Time to ROSC, min } \\
\hline $1-15$ & 77 & $13.2(8.2-22.6)$ \\
\hline $16-24$ & 72 & $15.0(11.9-28.5)$ \\
\hline $25-57$ & 73 & $17.7(11.5-34.3)$ \\
\hline$p$ value & & 0.038 \\
\hline \multicolumn{3}{|c|}{ Induced hypothermia } \\
\hline Yes & 175 & $15.2(10.5-31.7)$ \\
\hline No & 47 & $13.4(7.7-29.2)$ \\
\hline$p$ value & & 0.086 \\
\hline
\end{tabular}

Data are reported as median and (interquartile range). Age and time to ROSC are reported as categorical variables divided in their tertiles. $p$ value from Kruskal-Wallis test

ROSC return of spontaneous circulation

At ICU admission, plasma levels of HBP were significantly higher in patients with higher $24 \mathrm{~h}$ SOFA scores (Additional file 2). Moreover, HBP levels were significantly higher in patients who developed cardiovascular failure (Additional file 2) and in those who developed MODS compared to those who did not (Fig. 1). The area under the curve (AUC) of the ROC curve for discrimination of MODS was $0.70 \pm 0.04(p=0.0001)$. A plasma level of $17.6 \mathrm{ng} / \mathrm{mL}$ of HBP had a balanced sensitivity (0.73) and specificity (0.62) to predict development of MODS (Fig. 1). The odds ratios for prediction of MODS are reported in Table 3.

Plasma levels of HBP at ICU admission and $48 \mathrm{~h}$ later were significantly higher in patients who died compared to those who survived to ICU discharge (Fig. 2). The odds ratios for prediction of ICU mortality of HBP are detailed in Table 3 . In a multivariable model, including age, sex, the initial cardiac arrest rhythm (shockable or non-shockable), time to ROSC, use of adrenaline, and whether induced hypothermia was applied or not (Table 1), plasma levels of HBP at ICU admission were independently associated with ICU death, OR [95 \%CI] 1.607 [1.076-2.399] (Table 3). The study had a power of $80 \%$ (at $\alpha=0.05$ ) to detect an effect size of 1.55 (expressed as OR), for $1 \mathrm{SD}$ increase in HBP levels, on ICU death. The AUC of the ROC curve for discrimination of ICU death was $0.74 \pm 0.04(p<0.0001$, Fig. 2) and a value of $17.6 \mathrm{ng} / \mathrm{mL}$ predicted ICU death with a sensitivity of 0.79 and a specificity of 0.64 .

Plasma levels of HBP at ICU admission and at $48 \mathrm{~h}$ later were also significantly higher in patients who had a poor 12-month neurological outcome compared to those who had a good recovery (Fig. 2). However, in the multivariable model, HBP was not independently associated with 12-month poor outcome (Table 3). The AUC of the ROC curve for discrimination of 12 -month poor outcome was $0.65 \pm 0.04(p<0.0001$, Fig. 2$)$. The odds ratios for prediction of 12-month poor outcome at ICU admission and $48 \mathrm{~h}$ later are detailed in Table 3.

At ICU admission, serum lactate levels were also recorded in $72 \%$ of patients. When compared, no difference between the AUCs of HBP and those of lactate for discrimination of MODS, ICU death, and poor 12-month outcome $(p=0.36, p=0.99$, and $p=0.97$, respectively) were observed, as described in Additional file 3.

\section{Discussion}

The present study suggests that plasma levels of HBP rise early in patients resuscitated from cardiac arrest. Indeed, higher plasma levels of HBP at ICU admission were associated with higher 24 h SOFA score and development of MODS and were independently associated with death in ICU. Plasma levels of HBP were also significantly higher in patients with an unfavorable 12-month neurological outcome compared to those with a favorable outcome.

HBP is a granule protein mainly derived from neutrophils and is released from both secretory vesicles and azurophilic granules [8, 18]. Secretory vesicles release HBP rapidly upon cross-linking of $\beta 2$ integrins on the 


\section{HBP and development of multiple organ dysfunction syndrome}
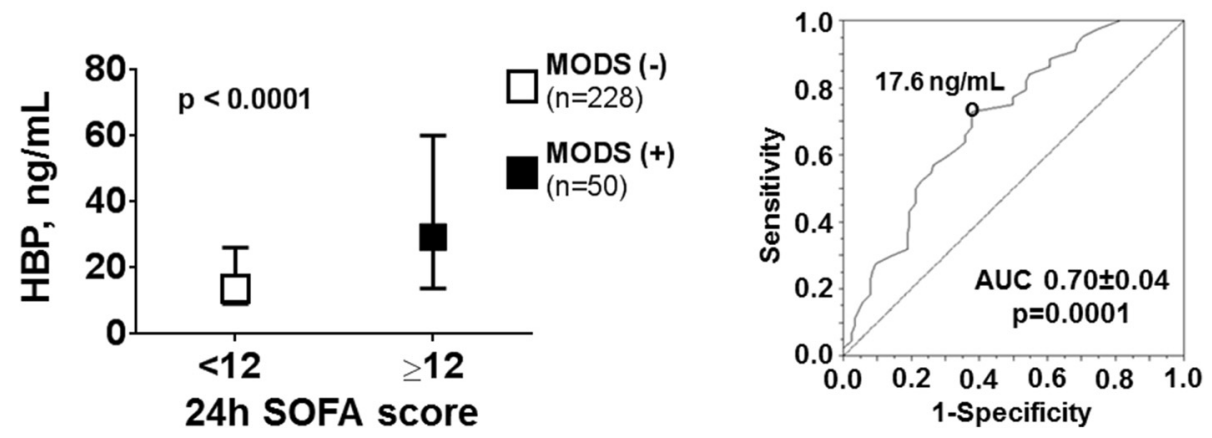

Fig. 1 Plasma levels of HBP at ICU admission in patients with or without multiple organ dysfunction syndrome (MODS), and corresponding receiver operating curve (ROC) and area under the curve (AUC). Data are reported as median and interquartile range; $p$ value from the Kruskal-Wallis test. HBP heparin-binding protein, SOFA Sequential Organ Failure Assessment

surface of neutrophils, while azurophilic granules release HBP more slowly. Whole-body ischemia during cardiac arrest leads to endothelial activation and systemic inflammation, and neutrophils are a determinant in the early step of the inflammatory process [19]. As early as $3 \mathrm{~h}$ after resuscitation, blood concentrations of soluble intercellular adhesion molecule-1, soluble vascular cell adhesion molecule-1, and P- and E-selectins increase, suggesting leukocyte and endothelial activation, which may account for a rapid HBP release [4, 20, 21]. In our study, the median HBP levels at ICU admission were already twofold compared to normal values. A potential role of HBP in the pathogenesis of post-resuscitation

Table 3 Univariate and multivariate logistic models for the prediction of multiple organ dysfunction syndrome (MODS), ICU death, and 12-month poor outcome

\begin{tabular}{|c|c|c|c|c|c|c|}
\hline & \multicolumn{3}{|c|}{ Univariate } & \multicolumn{3}{|c|}{ Multivariate } \\
\hline & $\overline{\mathrm{OR}}$ & $95 \% \mathrm{Cl}$ & $\overline{p \text { value }}$ & $\overline{\mathrm{OR}}$ & $95 \% \mathrm{Cl}$ & $p$ value \\
\hline \multicolumn{7}{|l|}{ MODS } \\
\hline $\mathrm{HBP}, 0 \mathrm{hr}$ & 1.339 & $1.023-1.753$ & 0.034 & 1.193 & $0.889-1.601$ & $0.240^{1}$ \\
\hline \multicolumn{7}{|l|}{ ICU death } \\
\hline $\mathrm{HBP}, \mathrm{O} \mathrm{hr}$ & 1.843 & $1.280-2.654$ & 0.001 & 1.607 & $1.076-2.399$ & $0.020^{2}$ \\
\hline $\mathrm{HBP}, 48 \mathrm{hr}$ & 1.066 & $0.726-1.565$ & 0.745 & 0.939 & $0.595-1.481$ & $0.786^{3}$ \\
\hline \multicolumn{7}{|c|}{ 12-month poor outcome } \\
\hline $\mathrm{HBP}, 0 \mathrm{hr}$ & 1.980 & $1.170-3.351$ & 0.010 & 1.454 & $0.890-2.375$ & $0.135^{3}$ \\
\hline $\mathrm{HBP}, 48 \mathrm{hr}$ & 1.337 & $0.965-1.851$ & 0.081 & 1.154 & $0.834-1.596$ & $0.387^{3}$ \\
\hline
\end{tabular}

OR, odds ratio per 1 SD increase (SD of HBP is 62.67 at $0 \mathrm{hr}$ and 76.14 at $48 \mathrm{hr}$ )

ICU intensive care unit, $\mathrm{Cl}$ confidence interval, $\mathrm{HBP}$ heparin-binding protein, $C A$ cardiac arrest, ROSC return of spontaneous circulation

Covariates included in the multivariate models are;

${ }^{1}$ CA presenting rhythm (shockable vs. not shockable), use of adrenaline, age, and sex

${ }^{2}$ CA presenting rhythm (shockable vs. not shockable), use of adrenaline, time to ROSC $(\mathrm{min})$, induced hypothermia, age, and sex

${ }^{3}$ CA presenting rhythm (shockable vs. not shockable), use of adrenaline, time to ROSC ( $\mathrm{min})$, induced hypothermia, age, and sex syndrome cannot be excluded since HBP is known to induce cytoskeletal rearrangement of endothelial cells with subsequent breakdown of cell barriers and increases of the macromolecular efflux $[8,18]$. Thus, HBP plays a central role in endothelial permeability regulation, increasing vascular permeability and leading to edema, hypoperfusion, tissue hypoxia, and organ dysfunction $[8,22]$.

Our study confirms earlier results obtained from 84 patients resuscitated from cardiac arrest, in whom an early elevation of HBP, i.e., at $6 \mathrm{~h}$ and $12 \mathrm{~h}$ after resuscitation, predicted organ failure and poor 6-month neurological outcome [10]. In that study, HBP levels at $6 \mathrm{~h}$ yielded an AUC value of 0.68 for discrimination of longterm poor neurological outcome, which is close to the moderate AUC of 0.65 observed in our cohort. However, in contrast to early results, at the multivariate analysis, high HBP levels were not independently associated with 12 -month poor outcome in our population. Our study was performed on a population more than threefold greater than Dankiewicz's study [10] and thereby the results are likely to be more robust. In addition, in our population, HBP performance in predicting MODS, ICU death, and 12-month outcome was similar to that of serum lactate (Additional file 3), which is one of the initial laboratory findings widely used to predict mortality in patients with different critical illnesses, including cardiac arrest [23, 24]. Thus, HBP admission level is associated with outcome, but it fails to emerge as a new prognostic tool superior to other routinely used biomarkers, i.e., lactate.

HBP levels have been reported to be significantly higher in ICU patients with severe sepsis or septic shock compared to patients with a non-septic illness. More specifically, a plasma HBP concentration of $\geq 15 \mathrm{ng} / \mathrm{mL}$ was associated with development of severe sepsis and circulatory failure and increased risk of death $[11,12]$. In our study, HBP levels were already $>15 \mathrm{ng} / \mathrm{mL}$ at ICU 


\section{ICU Outcome}

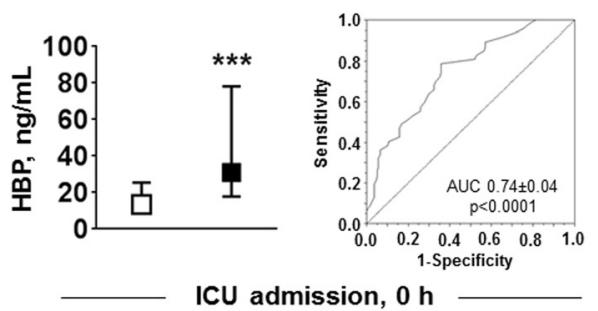

12-month Outcome
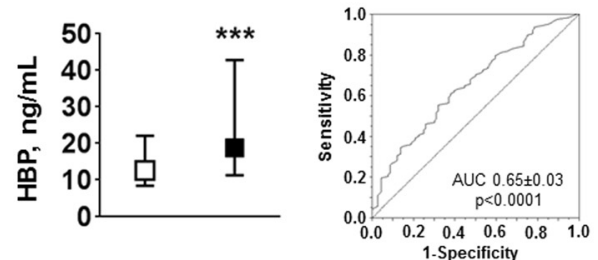

ICU admission, $0 \mathrm{~h}$ $\square$ Alive $(n=229) \quad$ Dead $(n=49)$

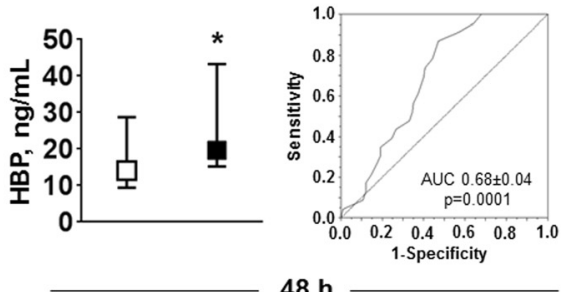

$48 \mathrm{~h}$

Unfavourable $(n=143)$
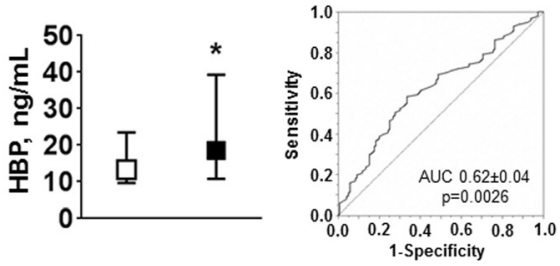

$48 \mathrm{~h}$

Fig. 2 Plasma levels of HBP at ICU admission ( $0 \mathrm{~h}$ ) and 48 hour later in ICU survivors and non-survivors (on the top) and in patients with favorable and non-favorable 12-month outcome (on the bottom), with corresponding receiver operating curves (ROC) curve and area under the curves (AUC). Data are reported as median and interquartile range; $p$ value from Kruskal-Wallis test: ${ }^{*} p<0.05 ;{ }^{* * *} p<0.0001$. HBP heparin-binding protein, ICU intensive care unit

admission, with values above $30 \mathrm{ng} / \mathrm{mL}$ in patients who subsequently died in the ICU. Indeed, a level of $\mathrm{HBP}>17.6 \mathrm{ng} / \mathrm{mL}$ at ICU admission was associated with higher risk of developing MODS, and with a $50 \%$ higher risk of dying in ICU, compared to patients with lower values.

Earlier studies have also reported that elevated concentrations of other inflammatory mediators, i.e., C-reactive protein or procalcitonin, also correlate with patients' clinical states and predicted poor outcome after cardiac arrest $[14,25]$. Circulating concentrations of those biomarkers, however, rise slowly, achieving values predictive of outcome only after 12 to 24 hours following resuscitation. In our study, patients exhibiting high HBP already at ICU admission subsequently developed a more severe shock and were more likely to die in ICU. Our results resemble those of earlier reports in septic patients, indicating HBP as the best early predictor of vascular failure and risk of developing circulatory failure and organ dysfunction, when compared to other laboratory parameters, including procalcitonin, interleukin-6 (IL-6), and C-reactive protein $[12,26]$. HBP has been now confirmed as an early biomarker that may have a clinical role in the prediction of imminent death after cardiac arrest, similarly to other early inflammatory biomarkers previously assessed by us in the same population, i.e., PTX3 and sST2 [15], but with limited prediction of long-term outcome, in contrast to others, i.e., IL- 6 or kynurenine metabolites $[6,27]$.
Plasma levels of the inflammatory marker HBP were higher in patients with non-shockable rhythm and with longer time to ROSC. As previously suggested, because non-shockable rhythms are usually associated with other pathological conditions, the high levels of inflammatory markers may reflect the presence of a general inflammatory status that preceded and/or led to cardiac arrest $[15,28]$. A longer duration of cardiac arrest, including both no-flow and low-flow times, is known to be associated with a greater severity of post-cardiac arrest syndrome, and plausibly accounted for the higher levels of HBP $[3,15,27,29]$.

We acknowledge several limitations in the interpretation of our findings. First, this was a biomarker substudy of the FINNRESUSCI study. Overall, the FINNRESUSCI population was characterized by a high rate of shockable cardiac arrests and a favorable outcome [13]. In addition, some difference between the patients included in this study and those not included were present (Additional file 1). Indeed, patients with blood samples were somewhat less severely ill than those without blood samples, as represented by the significantly greater percentage of shockable rhythms and survival to ICU and hospital discharge and to 1 year with a favorable neurological outcome. Nevertheless, early HBP elevation was consistently observed after resuscitation in patients who presented poor early outcome. In addition, all patients with a blood sample were included in the study and patients had been 
treated in 21 different ICUs, including academic and nonacademic hospitals covering the majority of a single country and thus suggesting generalizability of the results. Furthermore, in the biomarker analyses, data collection, outcome evaluation and statistics were performed independently. Second, we assayed HBP only at two time points after resuscitation. However, previous studies both in sepsis and cardiac arrest have proven the early prognostic role of this protein and more specifically within 6-12 h after hospital admission, with subsequent decreases $[10,26]$.

\section{Conclusions}

The present study demonstrated in a large population of out-of-hospital cardiac arrests, that elevated plasma levels of HBP at ICU admission were associated with high $24 \mathrm{~h}$ SOFA score and were independently associated with early death in ICU.

\section{Additional files}

Additional file 1: Baseline characteristics and clinical factors in all FINNRESUSCI patients and in patients with blood samples.

Description of data: a table reporting the main clinical characteristics of the patients included in the overall FINNRESUSCI trial and the patients included in the present biomarker substudy. (DOCX $14 \mathrm{~kb}$ )

Additional file 2: Plasma levels of heparin-binding protein (HBP) at ICU admission in relationship to the 24-hour SOFA score and 24-hour cardiovascular SOFA score. Description of data: at ICU admission, plasma levels of HBP were significantly higher in patients with higher $24 \mathrm{~h}$ SOFA scores. Moreover, HBP levels were significantly higher in patients who developed cardiovascular failure. (DOCX $19 \mathrm{~kb}$ )

Additional file 3: Receiver operating characteristic curves of the discrimination value of plasma HBP at intensive care unit (ICU) admission and lactate and multiple organ dysfunction syndrome (MODS), ICU death, and 12-month poor outcome. Description of data: there was no difference in the areas under the curve (AUCs) of HBP and lactate for the discrimination of MODS, ICU mortality or 12-month poor outcome. (DOCX 68 kb)

\section{Abbreviations}

AUC, area under the curve; $\mathrm{Cl}$, confidence interval; $\mathrm{CPC}$, Cerebral Performance Category; CPR, cardiopulmonary resuscitation; $h$, hour; $H B P$, heparin-binding protein; ICU, intensive care unit; IL-6, interleukin-6; $\mathrm{IQR}$, interquartile range; MODS, multiple organ dysfunction syndrome; $\mathrm{OR}$, odds ratio; ROC, receiver operating curve; ROSC, return of spontaneous circulation; SOFA, Sequential Organ Failure Assessment

\section{Acknowledgements}

The authors acknowledge the great collaborative efforts of all the participants of the FINNRESUSCI study and the FINNRESUSCI Laboratory Study Group, especially the study doctors and nurses in the participating ICUs.

The FINNRESUSCI Study Group: Satakunta Central Hospital—Vesa Lund Päivi Tuominen, Satu Johansson, Pauliina Perkola, and Elina Kumpulainen; East Savo Central Hospital_Markku Suvela Sari Hirvonen, and Sirpa Kauppinen; Central Finland Central Hospital—Raili Laru-Sompa and Mikko Reilama; South Savo Central Hospital_-Heikki Laine Pekka Kettunen, and lina Smolander; North Karelia Central Hospital—Matti Reinikainen and Tero Surakka; Seinäjoki Central Hospital—Kari Saarinen Pauliina Lähdeaho and Johanna Soini; South Carelia Central Hospital—Seppo Hovilehto Päijät-Häme; Central Hospital_Pekka Loisa Alli Parviainen and Pirjo Tuomi Vaasa; Central Hospital-Simo-Pekka Koivisto and Raku Hautamäki; Kanta-Häme Central
Hospital—Ari Alaspää and Tarja Heikkilä; Lappi Central Hospital—Outi Kiviniemi and Esa Lintula; Keski-Pohjanmaa Central Hospital_-Tadeusz Kaminski and Jane Roiko Kymenlaakso; Central Hospital—Seija Alila, Jussi Pentti, and Reija Koskinen; Länsi-Pohja's Central Hospital_Jorma Heikkinen; Helsinki University Hospital, Jorvi Hospital - Jukka Vaahersalo, Tuomas Oksanen, Tero Varpula Anne Eronen, Teemu Hult, and Taina Nieminen; Meilahti Hospital Medical ICU_Tom Bäcklund and Leevi Kauhanen; Meilahti Hospital ICU—Kirsi-Maija Kaukonen, Ville Pettilä Leena Pettilä, and Sari Sutinen; Turku University Hospital—Juha Perttilä and Keijo Leivo; Tampere University Hospital-Sanna Hoppu, Jyrki Tenhunen, Sari Karlsson, Atte Kukkurainen, Simo Varila, Samuli Kortelainen, and Minna-Liisa Peltola; Kuopio University Hospital-Pamela Hiltunen, Jouni Kurola, Esko Ruokonen, Elina Halonen, Saija Rissanen, and Sari Rahikainen; and Oulu University Hospital-Risto Ahola, Tero Ala-Kokko, and Sinikka Sälkiö.

We also thank Tieto Ltd, Helsinki for processing the database of the Finnish Intensive Care Consortium.

The authors are grateful to Axis-Shield Diagnostics (Dundee, Scotland), an Alere company, for providing the reagents for measuring heparin-binding protein.

\section{Funding}

The study was supported by unrestricted grant from "Amici del 461 Mario Negri" awarded to GR and in part with unrestricted grants from Finska Lakaresallskapet, Stiftelsen Dorothea Olivia, Karl Walter och Jarl Walter Perkléns minne and Medicinska Understodsforeningen Liv och Halsa awarded to Markus B Skrifvars.

\section{Authors' contributions}

GR and MBS contributed to the conception, design, data analysis, and interpretation of the data and drafted the manuscript. RL and SM contributed to the conception, design, data analysis, and interpretation of the data and revised the manuscript critically for important intellectual content. VP contributed to the conception, design, data analysis, and interpretation of the data; revised the manuscript critically for important intellectual content; and contributed to the data acquisition and database access and linkage. RB and ES revised the manuscript critically for important intellectual content and performed the biomarker assays. TV, SB contributed to the conception, design, data analysis, and interpretation of the data; revised the manuscript critically for important intellectual content. VM, MM, and SBar. revised the manuscript critically and performed the statistical analyses. JV, MT, and SH revised the manuscript critically for important intellectual content and contributed to the data acquisition and database access and linkage. All authors read and approved the final manuscript.

\section{Competing interests}

ES is an employee of Diagnostics Engineering \& Research, which consulted to Mitsubishi Chemical Europe, Radiometer, Axis-Shield Diagnostics, LSI Medience Corporation, Japan, Roche Diagnostics, and Shanghai Kehua Bio-Engineering, China. However, no potential conflict of interest to this study was reported. Markus B Skrifvars has received a speakers fee from Axis-Shield Diagnostics.

All other authors reported no conflicts of interest.

\section{Ethics approval and consent to participate}

The ethics committees of Päijät-Häme, Etelä-Karala, Satakunta, Kymenlaakso Central Hospitals, and Tampere and Turku University Central Hospitals in addition to Helsinki and Uusimaa Hospital District approved the study. Informed consent from the patient's next of kin was obtained for data collection and blood sampling.

\section{Author details}

${ }^{1}$ Department of Cardiovascular Research, IRCCS - Istituto di Ricerche Farmacologiche "Mario Negri", Milan, Italy. ${ }^{2}$ Department of Neurology, Helsinki University Hospital, Helsinki, Finland. ${ }^{3}$ Division of Intensive Care Medicine, Kuopio University Hospital, Kuopio, Finland. ${ }^{4}$ Division of Intensive Care Medicine, Department of Anaesthesiology, Intensive Care and Pain Medicine, University of Helsinki and Helsinki University Hospital, Topeliuksenkatu 5, PL 266, 00029 HUS, Helsinki, Finland. ${ }^{5}$ DIAneering Diagnostics Engineering \& Research, Heidelberg, Germany. ${ }^{6}$ Department of Intensive Care, Tampere University Hospital, Tampere, Finland. ${ }^{7}$ Intensive 
Care, Inselspital, Bern University Hospital, Bern, Switzerland. ${ }^{8}$ Australian and New Zealand Intensive Care Research Centre, School of Public Health and Preventive Medicine, Monash University, Melbourne, Victoria, Australia.

Received: 9 March 2016 Accepted: 19 July 2016

Published online: 07 August 2016

\section{References}

1. Sasson C, Rogers MA, Dahl J, Kellermann AL. Predictors of survival from out-of-hospital cardiac arrest: a systematic review and meta-analysis. Circ Cardiovasc Qual Outcomes. 2010:3:63-81.

2. Nolan JP, Soar J, Cariou A, Cronberg T, Moulaert VR, Deakin CD, et al. European Resuscitation Council and European Society of Intensive Care Medicine Guidelines for Post-resuscitation Care 2015: Section 5 of the European Resuscitation Council Guidelines for Resuscitation 2015. Resuscitation. 2015;95:202-22

3. Nolan JP, Neumar RW, Adrie C, Aibiki M, Berg RA, Böttiger BW, et al. Post-cardiac arrest syndrome: epidemiology, pathophysiology, treatment, and prognostication. A Scientific Statement from the International Liaison Committee on Resuscitation; the American Heart Association Emergency Cardiovascular Care Committee; the Council on Cardiovascular Surgery and Anesthesia; the Council on Cardiopulmonary, Perioperative, and Critical Care; the Council on Clinical Cardiology; the Council on Stroke. Resuscitation. 2008:79:350-79.

4. Adrie C, Adib-Conquy M, Laurent I, Cariou A, Dhainaou JF, Spaulding C. Successful cardiopulmonary resuscitation after cardiac arrest as a "sepsis-like" syndrome. Circulation. 2002;106:562-8.

5. Peberdy MA, Andersen LW, Abbate A, Thacker LR, Gaieski D, Abella BS, et al. Inflammatory markers following resuscitation from out-of-hospital cardiac arrest-A prospective multicenter observational study. Resuscitation. 2016;103:117-24.

6. Vaahersalo J, Skrifvars MB, Pulkki K, Stridsberg M, Rosjo H, Hovilehto S, et al. Admission interleukin-6 is associated with post resuscitation organ dysfunction and predicts long-term neurological outcome after out-ofhospital ventricular fibrillation. Resuscitation. 2014;85:1573-9.

7. Roberts BW, Kilgannon JH, Chansky ME, Mittal N, Wooden J, Parrillo JE, et al. Multiple organ dysfunction after return of spontaneous circulation in postcardiac arrest syndrome. Crit Care Med. 2013;41:1492-501.

8. Gautam N, Olofsson AM, Herwald H, Iversen LF, Lundgren-Akerlund E, Hedqvist $P$, et al. Heparin-binding protein (HBP/CAP37): a missing link in neutrophil-evoked alteration of vascular permeability. Nat Med. 2001;7:1123-7.

9. Linder A, Soehnlein O, Akesson P. Roles of heparin-binding protein in bacterial infections. J Innate Immun. 2010;2:431-8.

10. Dankiewicz J, Linder A, Annborn M, Rundgren M, Friberg H. Heparinbinding protein: a nearly indicator of critical illness and predictor of outcome in cardiac arrest. Resuscitation. 2013:84:935-9.

11. Linder A, Åkesson P, Inghammar M, Treutiger CJ, Linnér A, Sundén-Cullberg J. Elevated plasma levels of heparin-binding protein in intensive care unit patients with severe sepsis and septic shock. Crit Care. 2012;16:R90.

12. Linder A, Christensson B, Herwald H, Björck L, Akesson P. Heparin-binding protein: an early marker of circulatory failure in sepsis. Clin Infect Dis. 2009:49:1044-50.

13. Vaahersalo J, Hiltunen P. Tiainen M, Oksanen T, Kaukonen KM, Kurola J, et al. Therapeutic hypothermia after out-of-hospital cardiac arrest in Finnish intensive care units: the FINNRESUSCI study. Intensive Care Med. 2013;39:826-37.

14. Wada T, Gando S, Mizugaki A, Yanagida Y, Jesmin S, Yokota H, et al. Coagulofibrinolytic changes in patients with disseminated intravascular coagulation associated with post-cardiac arrest syndrome - fibrinolytic shutdown and insufficient activation of fibrinolysis lead to organ dysfunction. Thromb Res. 2013;132:e64-9.

15. Ristagno G, Varpula T, Masson S, Greco M, Bottazzi B, Milani V, et al. Elevations of inflammatory markers PTX3 and SST2 after resuscitation from cardiac arrest are associated with multiple organ dysfunction syndrome and early death. Clin Chem Lab Med. 2015;53:1847-57.

16. Chew MS, Linder A, Santen S, Ersson A, Herwald H, Thorlacius H. Increased plasma levels of heparin-binding protein in patients with shock: a prospective, cohort study. Inflamm Res. 2012;61:375-9.
17. Lin Q, Shen J, Shen L, Zhang Z, Fu F. Increased plasma levels of heparinbinding protein in patients with acute respiratory distress syndrome. Crit Care. 2013;17:R155.

18. Tapper $\mathrm{H}$, Karlsson A, Morgelin M, Flodgaard H, Herwald H. Secretion of heparin-binding protein from human neutrophils is determined by its localization in azurophilic granules and secretory vesicles. Blood. 2002:99:1785-93.

19. Bro-Jeppesen J, Kjaergaard J, Wanscher M, Nielsen N, Friberg H, Bjerre M, et al. Systemic inflammatory response and potential prognostic implications after out-of-hospital cardiac arrest: a substudy of the Target Temperature Management Trial. Crit Care Med. 2015:43:1223-32.

20. Gando S, Nanzaki S, Morimoto Y, Kobayashi S, Kemmotsu O. Out-of-hospital cardiac arrest increases soluble vascular endothelial adhesion molecules and neutrophil elastase associated with endothelial injury. Intensive Care Med. 2000:26:38-44.

21. Geppert A, Zorn G, Karth GD, Haumer M, Gwechenberger M, Koller-Strametz J, et al. Soluble selectins and the systemic inflammatory response syndrome after successful cardiopulmonary resuscitation. Crit Care Med. 2000;28:2360-5.

22. Ostergaard E, Flodgaard H. A neutrophil-derived proteolytic inactive elastase homologue (hHBP) mediates reversible contraction of fibroblasts and endothelial cell monolayers and stimulates monocyte survival and thrombospond in secretion. J Leukoc Biol. 1992:51:316-23.

23. Lee DH, Cho IS, Lee SH, Min YI, Min JH, Kim SH, et al. Correlation between initial serum levels of lactate after return of spontaneous circulation and survival and neurological outcomes in patients who undergo therapeutic hypothermia after cardiac arrest. Resuscitation. 2015;88:143-9.

24. Donnino MW, Andersen LW, Giberson T, Gaieski DF, Abella BS, Peberdy MA, et al. Initial lactate and lactate change in post-cardiac arrest: a multicenter validation study. Crit Care Med. 2014;42:1804-11.

25. Engel H, Ben Hamouda N, Portmann K, Delodder F, Suys T, Feihl F, et al. Serum procalcitonin as a marker of post-cardiac arrest syndrome and longterm neurological recovery, but not of early-onset infections, in comatose post-anoxic patients treated with therapeutic hypothermia. Resuscitation. 2013;84:776-81.

26. Linder A, Arnold R, Boyd JH, Zindovic M, Zindovic I, Lange A, et al. Heparin-binding protein measurement improves the prediction of severe infection with organ dysfunction in the emergency department. Crit Care Med. 2015;43:2378-86.

27. Ristagno G, Latini R, Vaahersalo J, Masson S, Kurola J, Varpula T, et al. Early activation of the kynurenine pathway predicts early death and long-term outcome in patients resuscitated from out-of-hospital cardiac arrest. J Am Heart Assoc. 2014;3:e001094.

28. Dell'Anna AM, Bini Vinotti J, Beumier M, Orbegozo-Cortes D, Donadello K, Scolletta S, et al. C-reactive protein levels after cardiac arrest in patients treated with therapeutic hypothermia. Resuscitation. 2014;85:932-8.

29. Hagihara A, Hasegawa M, Abe T, Nagata T, Wakata Y, Miyazaki S. Prehospital epinephrine use and survival among patients with out-of-hospital cardiac arrest. J Am Med Assoc. 2012;307:1161-8.

\section{Submit your next manuscript to BioMed Central and we will help you at every step:}

- We accept pre-submission inquiries

- Our selector tool helps you to find the most relevant journal

- We provide round the clock customer support

- Convenient online submission

- Thorough peer review

- Inclusion in PubMed and all major indexing services

- Maximum visibility for your research

Submit your manuscript at www.biomedcentral.com/submit 